\section{Dual training in general internal medicine and rheumatology: the Irish context}

I read with interest the study conducted by Sivera et al, ${ }^{1}$ pertaining to differences and similarities in rheumatology training programmes in European League Against Rheumatism (EULAR)-affiliated countries. In particular, as an Irish doctor who has recently completed our national programme and had the fortune to work under some excellent rheumatologists, I was dismayed but not surprised to see that general internal medicine (GIM) plays such a dominant role in official rheumatology training in Ireland. We lead all 41 countries surveyed, where trainees commit a total of 84 months to GIM from the time of graduation from medical school, with 4 years of GIM commitment dedicated to the official rheumatology programme in Ireland. As a comparison, Norwegian trainees, with an equivalent population size, complete 28 months' GIM training in total and only 24 months of GIM during rheumatology training. Countries with an equivalent Gross Domestic Product (GDP) per capita (in 2013), the Netherlands and Sweden, ${ }^{2}$ spend approximately 50 months less in GIM training overall compared with the Irish. Despite this lower burden of GIM on the aforementioned comparator countries, both Norway and the Netherlands have longer rheumatology training programmes. The presented data provoke the question: can one train adequately as a rheumatologist when so much time is devoted to GIM rotas and on-call duties? Perhaps the fact that most Irish rheumatology trainees seek further experience abroad provides a partial but significant answer. Despite the obvious benefits of gaining experience in GIM as part of training in a multi-systems specialty like rheumatology, allowing GIM to dominate rather than complement training is surely to the detriment of our specialty. While the argument that the subspecialisation of specialties, including rheumatology, is eroding the application of the general skills relevant to that field of interest has validity, I believe the counterargument is stronger: that in order to have competence in the relevant medical advances in one's field of interest, subspecialisation is a necessity.
While there are many reasons for Ireland's onerous GIM burden, including historic (most consultant positions require both GIM and rheumatology cover) and economic, the findings are pertinent particularly in the current Irish context where consultant positions across the medical and surgical specialties remain unfilled, and Irish medical graduates are leaving the country in unprecedented numbers to pursue postgraduate training in work-friendlier environments. Whether a dual commitment to both GIM and rheumatology imbues expertise in both is unknown. I would suggest that pursuit of both detracts from achieving adequate training in rheumatology.

\section{Barry J Sheane}

Correspondence to Dr Barry J Sheane, Sports Surgery Clinic, Dublin 9, Ireland; barrysheane@sportssurgeryclinic.com

Competing interests None declared.

Provenance and peer review Not commissioned; internally peer reviewed.

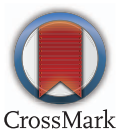

To cite Sheane BJ. Ann Rheum Dis 2015;74:e55.

Received 14 April 2015

Accepted 17 April 2015

Published Online First 6 May 2015

\section{S Linked}

http://dx.doi.org/10.1136/annrheumdis-2015-207813

Ann Rheum Dis 2015;74:e55. doi:10.1136/annrheumdis-2015-207782

\section{REFERENCES}

1 Sivera F, Ramiro S, Cikes N, et al. Differences and similarities in rheumatology specialty training programmes across European countries. Ann Rheum Dis 2015. Published Online First: 6 Mar 2015. doi:10.1136/annrheumdis-2014-206791

2 http://data.worldbank.org/indicator/NY.GDP.PCAP.PP.CD? order=wbapi_data_value_ 2013+wbapi_data_value+wbapi_data_value-last\&amp;sort=desc 